\title{
Experience with resuscitation bundle education
}

Song Yi Park ${ }^{1,2}$ and Jinwoo Jeong ${ }^{1}$

Departments of ${ }^{1}$ Emergency Medicine and ${ }^{2}$ Medical Education, Dong-A University College of Medicine, Busan, Korea

\section{Introduction}

Last year, the Korean Health Personnel Licensing Examination Institute announced an amendment to the clinical skill examination (CSE) portion of the Korean Medical Licensing Examination (KMLE). Among the changes, three skills (i.e., basic life support [BLS], tracheal intubation, and manual defibrillation) that were previously assessed individually were combined into one skill examination [1]. We named these three resuscitation skills the resuscitation bundle.

Current third-year medical students will be the first candidates for the revised CSE portion of the KMLE. As emergency physicians and medical educators, we had substantial concerns about preparing the students for the skill examination. Therefore, while conducting formative evaluations for the fourth-year medical students who had already learned the individual skills that are now included in the resuscitation bundle, we planned to explore what aspects of the skills students were struggling with. We would like to share the experience that we gained through this examination.

\section{Settings}

The subjects comprised 45 fourth-year medical students who were participating in the emergency medicine (EM) clinical clerkship course. Six to seven students participate in the EM clinical clerkship course every 2 weeks. These participating students already learned the resuscitation procedures in their third year of school.

At the beginning of each instance of the course, i.e., every 2 weeks, one faculty member demonstrated the combined resuscitation bundle to the students for 30 minutes. For the rest of the course, the students practised the bundle themselves using manikins and a defibrillator trainer.

In the second week of the course, the students were evaluated on their use of the resuscitation bundle at one station in the simulation centre. The evaluation was structured similar to an objective structured clinical examination station. Two faculty members participated in the evaluation. One faculty member acted as a rater, and the other faculty member acted as the student's assistant. The faculty members developed a scenario and
Received: July 24, 2020 • Revised: July 24, $2020 \bullet$ Accepted: August 24, 2020 Corresponding Author: Jinwoo Jeong (https://orcid.org/0000-0003-1745-5127) Department of Emergency Medicine, Dong-A University Hospital, Dong-A University College of Medicine, 26 Daesingongwon-ro, Seo-gu, Busan 49201, Korea Tel: +82.51.240.5590 Fax: +82.51.240.5309 email: jinwoo@dau.ac.kr
Korean J Med Educ 2020 Dec; 32(4): 343-347.

https://doi.org/10.3946/kjme.2020.181

eISSN: 2005-7288

(C) The Korean Society of Medical Education. All rights reserved. This is an open-access article distributed under the terms of the Creative Commons Attribution Non-Commercial License (http:// creativecommons.org/licenses/by-nc/3.0/), which permits unrestricted non-commercial use, distribution, and reproduction in any medium, provided the original work is properly cited. 
Fig. 1. Configuration of the Skill Station

(A)

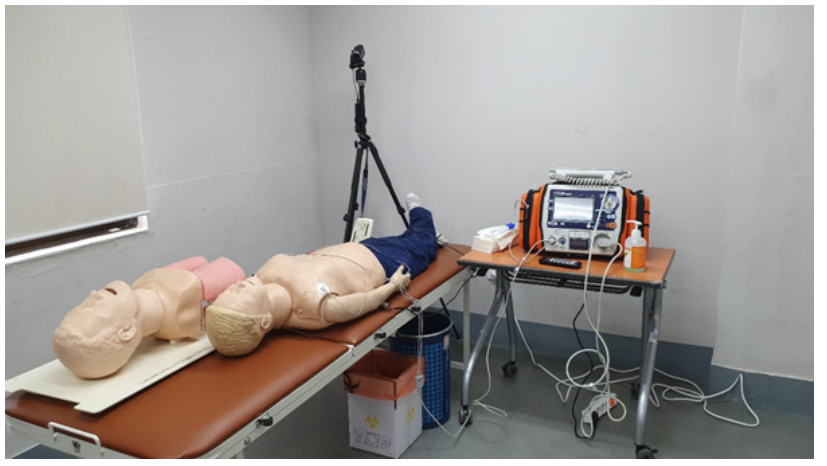

(A) A manikin for basic life support and defibrillation, and a separate airway trainer were prepared. (B) A wider view of the skill station including the rater's desk and chair.

checklist to implement all three skills. The faculty member who served as the rater is qualified as an advanced cardiovascular life support (ACLS) instructor and has over 10 years of student education experience. The other faculty member who is assistant with the assessment is qualified as a Korean advanced life support instructor and has 3 years of student education experience. The station evaluation lasted 12 minutes, and the evaluated student immediately received feedback on his/her performance from both faculty members after his/her evaluation.

BLS and manual defibrillation were performed on a Recording Resusci Anne (Laerdal Medical, Stavanger, Norway). A defibrillation trainer (CU Medical Systems, Wonju, Korea) was used as the manual defibrillator. Defibrillation was performed manually using paddles. Tracheal intubation was performed on a separately prepared Airway Trainer (Laerdal Medical) (Fig. 1A, B).

\section{Our findings}

\section{Student performance}

The students seemed to satisfy all the important points
(B)

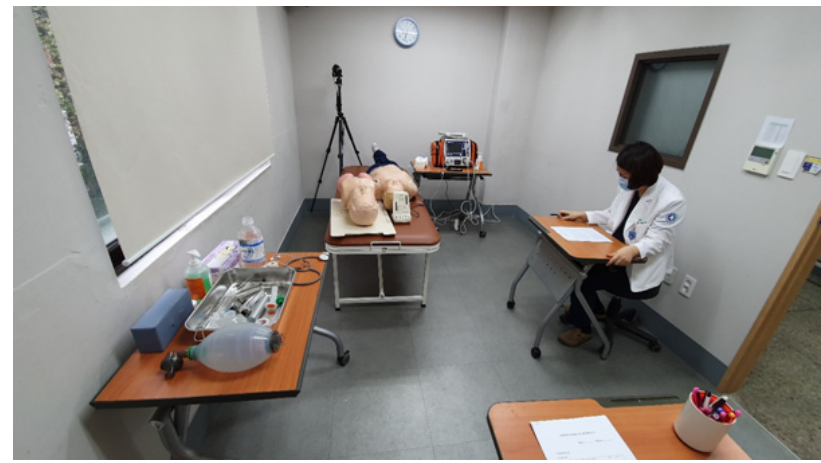

on the checklist. This outcome may be because they are fourth-year students who are about to take the CSE portion of the KMLE in the near future. Some aspects in which the students did not perform well are described below.

\section{1) Delayed rhythm analysis}

The student should stop chest compressions and immediately apply the defibrillator to check for a rhythm as soon as the defibrillator arrives. However, some students applied the defibrillators only after completing the cycle of chest compressions and ventilation.

\section{2) Mouth-to-mouth ventilation}

We educated and prepared to use bag-mask ventilation (BMV) and not mouth-to-mouth ventilation (MMV). If only a sole lay rescuer is present or multiple lay rescuers are reluctant to perform MMV, then the American Heart Association guidelines encourage chest compressiononly cardiopulmonary resuscitation (CPR) [2,3]. MMV is rarely used in cases of in-hospital arrests. Moreover, the recent interim guidelines for CPR for patients with suspected coronavirus disease 2019 (COVID-19) recommend against the use of MMV [4]. However, despite the prior notice, a few students utilized MMV on the manikin. 


\section{3) Failure to distribute roles}

The students continued one-person CPR even after the assistant was ready to help them provide CPR. This performance of the students is not totally wrong; however, when two personnel are present in the setting, one is responsible for performing chest compressions while the other is responsible for BMV or tracheal intubation. Students should check for a rhythm every 2 minutes and alternate chest compressions to achieve high-quality compression and prevent the exhaustion of the providers. However, approximately half of the students did not do this.

\section{4) Why did you intubate?}

After completing the tracheal intubation, many students removed the BMV device from the manikin and put it back on the preparation table. The students had to either ventilate themselves or ask their assistant for ventilation. They seemed to not apprehend the purpose of intubation.

\section{5) Hands-off time}

The guideline recommends not stopping chest compression for more than 10 seconds, but the students did not perform well in this regard.

\section{Equipment}

\section{1) Small space}

The space of examination was $2.7 \times 4.4 \mathrm{~m}^{2}$. However, the room was filled with BLS equipment, tracheal intubation manikins, a defibrillator, preparation tables, the rater' $\mathrm{s}$ desk and a chair. To maintain social distance in the era of COVID-19, twice as much space would be required.

\section{2) Limitation of manikins}

Tracheal intubation was performed on a separately prepared manikin. However, some students did not recognize these two manikins as one patient. Thus, the students asked the assistant for BMV on the intubation manikin, and at the same time, they performed chest compressions and MMV on the BLS manikin. In addition, the BLS manikin could not generate a palpable pulse, although the existence of a pulse was prompted verbally by the rater. An ACLS simulator that can generate pulses and accommodate tracheal intubation would provide more authentic experiences.

\section{3) Limitation of defibrillator}

The BLS manikin has no electrodes to recognize the defibrillator's electrical current. The normal automated electrical defibrillator trainer works without problems on such a manikin, but the defibrillation trainer recognizes the electrical resistance between the two paddles. Therefore, it sometimes displays the message "defibrillation not delivered" on the screen. When this message popped up, some students were embarrassed and could not perform the next task. It is necessary to ensure that the equipment does not interfere with the students' performance.

\section{In the scenario}

\section{1) Reactive module}

We designed this module for formative evaluation, and the rater actively intervened and provided feedback. The rater signalled to the students the "2 minutes elapsed" mark, provided a rhythm, and instructed the students to alternate chest compressions and ventilation when they did not. However, this is only possible when the rater has a good understanding of the module. The assistant running the module is a more feasible alternative than the rater in leading the module.

\section{2) Role of the assistant}

We established the assistant as a nurse. He/she brought a defibrillator, attached the monitor electrodes to the manikin, and alternately performed chest compressions and ventilation at the student's request. Students are expected to check for a pulse every 2 minutes and to 
decide whether to continue chest compressions or engage in defibrillation, at which time they delegate the pulse checking to the assistant. In the ACLS guidelines, the CPR leader can request team members to check the patient's pulse. However, for the purpose of education and evaluation, even delegable skills need to be implemented by the student in the current evaluation.

\section{3) Difficulty and reliability}

We prepared a total of eight rhythm combinations and randomly provided two rhythms to each student. This approach was chosen because the examination was conducted every 2 weeks and we were concerned about the repeated exposure of the rhythms. We wanted to evaluate whether the students could judge the shockable and non-shockable rhythms rather than demonstrate memorization [5]. However, the different rhythm combinations did not have the same level of difficulty. Thus, the level of difficulty could have affected the reliability of the outcomes.

\section{Discussion}

It was difficult to provide education regarding the resuscitation bundle using the existing equipment described above. Someone had to constantly intervene to advance the examination forward. The necessary equipment needs to be improved.

$\mathrm{CPR}$ is not a single-provider procedure. Teamwork and active communication between team members are emphasized in the ACLS course. However, when developing this module, we were not sure at what level to set the assistant's role. If the CSE portion of the KMLE is intended to evaluate only the students' proficiency of their psychomotor skills, the assistant may be set up as CPR leader who directs the students to perform skills such as chest compressions, BMV, and tracheal intubation. However, if the CES evaluates the student's competency to lead the process of resuscitation, then the role of the assistant should be different from that in the former situation.

Therefore, it was difficult for us to determine the goal of the resuscitation bundle education. Should students be educated as CPR leaders? If not, how much should they be educated and to what depth should they be evaluated? The goal and objective of both the education and evaluation need to be clearer. There should be minimum guidelines provided for medical educators and students.

\section{ORCID:}

Song Yi Park: https://orcid.org/0000-0003-4299-9986; Jinwoo Jeong: https://orcid.org/0000-0003-1745-5127

Acknowledgements: We would like to express our deep appreciation to Ms. Hyun Jin Park for her great help during the clinical clerkship.

Funding: No financial support was received for this study.

Conflicts of interest: No potential conflict of interest relevant to this article was reported.

Author contributions: SYP drafted the manuscript, and JJ reviewed and supplemented the manuscript.

\section{References}

1. Korea Health Personnel Licensing Examination Institute. KHPLEI Web Site. http://www.kuksiwon.or.kr. Accessed July 2, 2020.

2. Olasveengen TM, de Caen AR, Mancini ME, et al. 2017 International consensus on cardiopulmonary resuscitation and emergency cardiovascular care science with treatment recommendations summary. Circulation. 2017; 136(23):e424-e440. 
Song Yi Park and Jinwoo Jeong: Experience of resuscitation skill education

3. Kleinman ME, Brennan EE, Goldberger ZD, et al. Part 5: adult basic life support and cardiopulmonary resuscitation quality: 2015 American Heart Association guidelines update for cardiopulmonary resuscitation and emergency cardiovascular care. Circulation. 2015;132(18 Suppl 2): S414-S435.

4. Nolan JP, Monsieurs KG, Bossaert L, et al. European
Resuscitation Council COVID-19 guidelines executive summary. Resuscitation. 2020;153:45-55.

5. Khan KZ, Ramachandran S, Gaunt K, Pushkar P. The objective structured clinical examination (OSCE): AMEE guide no. 81. Part I: an historical and theoretical perspective. Med Teach. 2013;35(9):el437-el446. 